\title{
Glass Half-Full or Half-Empty? A Fire-Resistant Species Triggers Divergent Regeneration in Low-Resilience Pastures
}

\begin{abstract}
Andrea Sánchez-Tapia ${ }^{1,2 *}$, Jerônimo Boelsums Barreto Sansevero ${ }^{2,3}$, Mário Luís Garbin ${ }^{4}$, João Marcelo Alvarenga Braga ${ }^{1,2}$, Pablo Hugo Alves Figueiredo ${ }^{2}$ and Fabio Rubio Scarano ${ }^{5}$

1 Instituto de Pesquisas Jardim Botânico do Rio de Janeiro, Rio de Janeiro, Brazil, ${ }^{2}$ Escola Nacional de Botânica Tropical, Instituto de Pesquisas Jardim Botânico do Rio de Janeiro, Rio de Janeiro, Brazil, ${ }^{3}$ Laboratório de Ecologia Aplicada, Departamento de Ciências Ambientais, Instituto de Florestas, Universidade Federal Rural do Rio de Janeiro, Rio de Janeiro, Brazil, ${ }^{4}$ Departamento de Biologia, Centro de Ciências Exatas, Naturais e da Saúde, Universidade Federal do Espírito Santo, Alegre, Brazil, ${ }^{5}$ Departamento de Ecologia, Instituto de Biologia, Centro de Ciências da Saúde, Universidade Federal do Rio de Janeiro, Rio de Janeiro, Brazil
\end{abstract}

OPEN ACCESS

Edited by:

Debora Cristina Rother,

University of São Paulo, Brazil

Reviewed by:

Bernd Panassiti,

Independent Researcher,

Munich, Germany

Noel Douglas Preece,

James Cook University, Australia

${ }^{*}$ Correspondence:

Andrea Sánchez-Tapia

andreasancheztapia@jbrj.gov.br

Specialty section:

This article was submitted to

Forest Disturbance,

a section of the journal

Frontiers in Forests and Global

Change

Received: 11 May 2020 Accepted: 14 September 2020

Published: 22 October 2020

Citation:

Sánchez-Tapia A, Sansevero JBB,

Garbin ML, Braga JMA,

Figueiredo PHA and Scarano FR (2020) Glass Half-Full or Half-Empty?

A Fire-Resistant Species Triggers

Divergent Regeneration in

Low-Resilience Pastures.

Front. For. Glob. Change 3:560912. doi: 10.3389/ffgc.2020.560912
Fire may divert or arrest natural regeneration in abandoned pastures throughout the tropics, transforming them to low-resilience systems that do not recover even in the absence of disturbances. Understanding regeneration in degraded landscapes is crucial to decision-making and predicting the outcome of passive or active restoration actions. We aimed to understand the effects of intensifying fire regimes on post-fire natural regeneration in sites degraded by logging and fire in the Brazilian Atlantic Forest. We studied five areas with different fire regimes (i.e., different fire frequencies and post-fire regeneration time), dominated by Moquiniastrum polymorphum (Asteraceae), a widely-distributed species with fire resistance traits. We analyzed differences in structure, diversity, the amplitude of the species' geographic distribution, and floristic composition. We recorded Leaf Area Index and grass cover to understand the effect of canopy closure on fire exclusion and analyzed functional traits related to succession and response to fire (specific leaf area, height, wood density, bark thickness, seed mass). Post-fire regeneration was slow and fire-prone and dominance by $M$. polymorphum decreased with less disturbance, as other species entered the communities. Structure, diversity, and functional composition recovered along the gradient but did not reach old-growth values. The taxonomic composition was strikingly different in burned areas and forests, irrespective of fire history. Natural regeneration followed a divergent trajectory, marked by the establishment of other widely-distributed species, which suggests a long-term floristic impoverishment. The establishment of $M$. polymorphum allows these pastures to exit grass-fire cycles. Longer post-fire recovery and fewer fire events allow for canopy closure, grass exclusion, and eventually fire suppression. This two-step dynamic breaks a crucial barrier for restoration from degraded pastures and represents a more desirable state than pastures. However, relying only upon natural regeneration results in impoverished secondary forests. Given the pervasive effects of deforestation and fire, natural regeneration observed in tropical landscapes may correspond to 
impoverished new secondary forests that fail to attain conservation targets for the biome. Preventing future fires and controlling grass cover in the understory is crucial to avoid their retrogression to pastures and to treat them as regeneration templates for active restoration.

Keywords: Brazilian Atlantic Forest, dominance shifts, monodominance, savannization, tropical secondary forests, novel forests, fire in tropical forests

\section{INTRODUCTION}

Throughout the tropics, many forest areas have been cleared to pastures and are subjected to modified fire regimes as they recover (Cochrane, 2003). Fire affects both anthropogenic pastures and fire-prone degraded forests at varying frequencies and intensities (Nepstad et al., 1999; Barlow and Peres, 2008). In the most extreme cases, repeated fires may trap these pastures in low-resilience points dominated by fire-grass feedbacks (D'Antonio and Vitousek, 1992; Flores et al., 2016). Forest species lack the mechanisms to respond to these modified fire regimes and degraded pastures remain as low-diversity "derived savannas" (Veldman and Putz, 2011) that fail to recover even after long periods without fire (Lamb et al., 2005). These areas have been described as "treeless" states (Hirota et al., 2011), and the processes that create them have been described under the terms "secondarization" (Barlow and Peres, 2008), and "retrogressive succession"-a return to early successional states (Santos et al., 2008; Tabarelli et al., 2008; Ewers et al., 2016). The conversion of forests to such stable degraded pastures has been reported in the Amazon (Barlow and Peres, 2008; Veldman and Putz, 2011; Flores et al., 2016) and tropical dry forests (Cavelier et al., 1998).

Abandoned pastures trapped in fire-grass cycles exhibit opposing fire dynamics to old-growth forests, that have low to null flammability (Uhl et al., 1988; Nepstad et al., 1999; Barlow and Peres, 2008). Transitions between the two extremes may be gradual or abrupt, and they may be composed of a mix of species from both sides of the gradient or have a distinct floristic identity (Pausas, 2015). In some cases, pastures represent anthropogenic stable states alternative to forests, just like natural savannas and forests are considered alternative stable states in savannaforest ecotones (Hoffmann et al., 2012; Pausas, 2015; Reyer et al., 2015). Considering that anthropogenic pastures cover a substantial portion of tropical forest regions, understanding the main mechanisms and barriers to natural regeneration has fundamental implications for ecological restoration actions.

The most detailed recent survey estimates that $28 \%$ of the original area of the Brazilian Atlantic Forest (BAF) corresponds to native vegetation (Rezende et al., 2018). In the BAF, fire severity is one of the most critical processes affecting natural regeneration (dos Santos et al., 2019). Under the scope of fragmentation and edge effects, abandoned pastures are anthropogenic matrices that surround forest fragments (Tabarelli et al., 2010; Melo et al., 2013), but it is more important than ever to treat them as potentially regenerating vegetation. There is a considerable effort to foster natural regeneration as a paradigm for forest cover recovery in the BAF (Crouzeilles et al., 2019). Still, the existence of low-resilience areas may represent a challenge to attain these restoration goals, since a crucial part of the decision-making process regarding restoration is to predict active or passive restoration success and allocate resources accordingly (Suding et al., 2004; de Rezende et al., 2015).

In this study, we analyze the effect of different fire regimes (i.e., different fire frequencies and years since the last fire) on post-fire regeneration in abandoned pastures in lowland areas of the BAF. Moquiniastrum polymorphum (Less.) G. Sancho (Asteraceae), is dominant in the secondary vegetation at the interface between pastures and forests in the PABR. This species is common in the Cerrado (Brazilian Savanna) and in degraded pastures in the BAF (Sansevero et al., 2017, 2020). It can survive fires and form fire rings, which allows its use in fire history reconstruction (Brandes et al., 2019). Its thick bark allows for survival to frost events as well (Brando and Durigan, 2005). In the PABR, M. polymorphum creates areas that appear to have a low resilience to disturbance (Sansevero et al., 2020). The dynamics of natural regeneration and the implications for ecological restoration in this transition from pastures to forests have not been addressed yet.

We analyze the changes in structure, diversity, species, and functional trait composition along the fire gradient. We expect the recovery of diversity, structure, and taxonomic composition along the fire disturbance gradient intensity, with less fire events and more time for post-fire succession. We also expect leaf area index (LAI), a proxy for canopy density, to increase along the gradient, and grass cover, which represents fuel for further fires and increases community flammability, to decrease. We also expect changes in the functional response attributes from traits related to fire resistance (thicker barks, smaller seeds, low SLA) in the most disturbed sites, toward trait compositions related to old-growth forests with milder fire regimes, such as high wood density and high seed mass. We also test whether species entering the secondary vegetation are the same that are already present in nearby old-growth forests, and evaluate if they are forest specialists or not through their geographic distribution area, as a proxy for niche breadth and habitat specialization. Finally, we discuss the implications of our findings for active or passive restoration strategies in these degraded landscapes and discuss the positive (glass-half full) and negative (glass half-empty) effects of the presence of $M$. polymorphum in the post-fire regeneration of abandoned pastures in the BAF.

\section{MATERIALS AND METHODS}

\subsection{Study Area}

Poço das Antas Biological Reserve (PABR, $22^{\circ} 30^{\prime} \mathrm{S}, 42^{\circ} 19^{\prime} \mathrm{W}$ ) was created in 1974 to protect lowland fragments of Atlantic Forest in the Rio de Janeiro state and its threatened fauna, including the 
golden lion tamarin (Leontopithecus rosalia L., Callithricidae). The climate in the PABR corresponds to tropical savanna climate with dry winters (Aw) (Köppen, 1936), with mean monthly temperatures between $21.8^{\circ} \mathrm{C}$ in July and $29^{\circ} \mathrm{C}$ in February, and mean annual precipitation of 2,160 $\mathrm{mm}$, with a dry season between June and July $(38.9 \mathrm{~mm})$ and rainy summers $(320 \mathrm{~mm}$ in February) (Lima et al., 2006).

PABR has a long history of land use that includes clearing forests for raising cattle and the canalization of rivers to drain swampy areas since the early twentieth century (Brazilian Ministry of the Environment, 2005). Small-scale slash-and-burn practices have existed in the region for at least a century, but large-scale fires began in 1984, following the construction of the Juturnaíba dam that drained and exposed large tracts of highly flammable peatlands (Dean, 1996, p. 374). As a result, only 52\% of the PABR is covered by old-growth forest remnants, the rest corresponding to secondary vegetation, anthropogenic pastures, and grass-dominated peatlands (Lima et al., 2006). However, there is no record of fire entering the old-growth forests, even in small insular fragments surrounded by pastures. The transition from pasture to forests comprises secondary vegetation with different fire histories, with structures that vary from almost $100 \%$ grass cover with isolated trees to closed-canopy woodlands and secondary forests. M. polymorphum is the dominant tree species in these secondary areas.

\subsection{Fire History and Area Selection}

We established the fire history in the PABR by analyzing maps made since 1990, when the most extensive fire to date happened. This fire covered ca. 1,500 ha and triggered the creation of Prevfogo, the Brazilian program for preventing fires in preserved land, according to the PABR's management plan (Brazilian Ministry of the Environment, 2005). After this large fire event, the staff at the reserve began mapping the extent and perimeter of every fire. We found data for fires that occurred in 1993, 2002, 2010. To recognize the areas affected in 1990, we asked and checked with the PABR staff in the field. For fires that occurred after 1990, we digitalized and georeferenced the maps made by the PABR staff following Prevfogo and the Brazilian Environmental Institute and Chico Mendes Institute (IBAMA/ICMBio) protocols (Figure 1). To assess the general state of the studied areas before 1974, we analyzed an aerial photograph taken in 1956. We conducted the present study between July and November 2010 (Figure 1).

Peatlands and contiguous anthropogenic pastures have the highest fire frequencies in the PABR. They are treeless areas, and grasses, such as Imperata brasiliensis Trin. and Melinis minutiflora P. Beauv. dominate and recolonize them rapidly after each fire event. They represent a stable state governed by grass-fire cycles and are part of the fire gradient, but we focus on the subset of pastures that have a few trees breaking this cycle. Overall, this kind of frequently burned abandoned pastures occupy 1,613 ha of the area of the PABR (32.3\%), while the early regenerating states occupy $213 \mathrm{ha}, 4.3 \%$ of its area (Lima et al., 2006).

Following the 2010 fire, we selected five areas according to their fire history:
1. secondary woody scrubs that burned four times, the last of which was 0.5 years before the measurements (in 2010). This area that was subjected to four fire events $(1990,1993,2002$, 2010) and had less time for recovery will be hereafter named high disturbance areas;

2. secondary woody scrubs that burned three times (1990, $1993,2002)$, the last of which occurred 8 years before the measurements (2002). The areas with this fire history were classified as medium disturbance areas;

3. secondary woody scrubs that burned once, 20 years before the surveys (1990). Because of the low number of fire events and the longer time for recovery, we classified the vegetation with this fire history as low disturbance areas;

4. secondary forests, which were pastures in 1956 according to the aerial photograph, and are regenerating in the absence of fire at least since 1974 (date of the creation of the PABR, 36 years before the surveys);

5. mature forests, with no evidence of significant anthropogenic disturbance for at least 54 years, according to the 1956 aerial photograph.

The studied areas have simultaneously different fire frequencies and different recovery times $(0,8,20,>36$, and $>54$ years). Likewise, distance to the nearest propagule source is also correlated to a higher fire frequency and less time for recovery (Table 1). We consider that this gradient does not form a classic space-for-time substitution (a chronosequence) because the areas along it have different disturbance histories (Walker et al., 2010). They instead form a complex fire gradient, in which the number of fire events and time since the last disturbance are inversely related. We consider this gradient as a natural experiment (Legendre and De Cáceres, 2013). The fact that there are no sites in the PABR and its surroundings to complete a full factorial design reinforces the idea that there is an established positive feedback between fire and grasses in these pastures (Figure 1).

\subsection{Vegetation Survey}

In each one of the five kind of areas with the same fire history (High, Medium, Low Disturbance, Secondary Forests and Mature Forests), we marked three $30 \times 60 \mathrm{~m}$ plots, with at least $100 \mathrm{~m}$ between them (Figure 1). We divided each plot in three $20 \times 30$ $\mathrm{m}$ blocks and each block in six $10 \times 10 \mathrm{~m}$ subplots. We sampled randomly two subplots in each block $(20 \times 30 \mathrm{~m})$, thus surveying six $10 \times 10 \mathrm{~m}$ subplots $\left(600 \mathrm{~m}^{2}\right)$ per plot, for a total of 90 subplots in 15 plots.

In each $10 \times 10 \mathrm{~m}$ subplot, we surveyed all the individuals of trees, shrubs, and palms, with diameter at breast height (dbh) $\mathrm{dbh} \geq 5 \mathrm{~cm}$. The dbh was measured at $150 \mathrm{~cm}$ from the trunk base and consistently on the downslope-facing side of the trunk. Stems from multi-stemmed individuals were measured and the individuals were included if their equivalent dbh (the equivalent diameter of a circle with the same basal area taken from all the individual stems) was also $\geq 5 \mathrm{~cm}$. We also measured leaf area index (LAI) at the center of each subplot, by analyzing hemispheric photographs taken under overcast weather, $1 \mathrm{~m}$ above the ground. The photos were taken by a fisheye lens Nikon FC-08 coupled to a Nikon Coolpix 4500 camera, and LAI was 


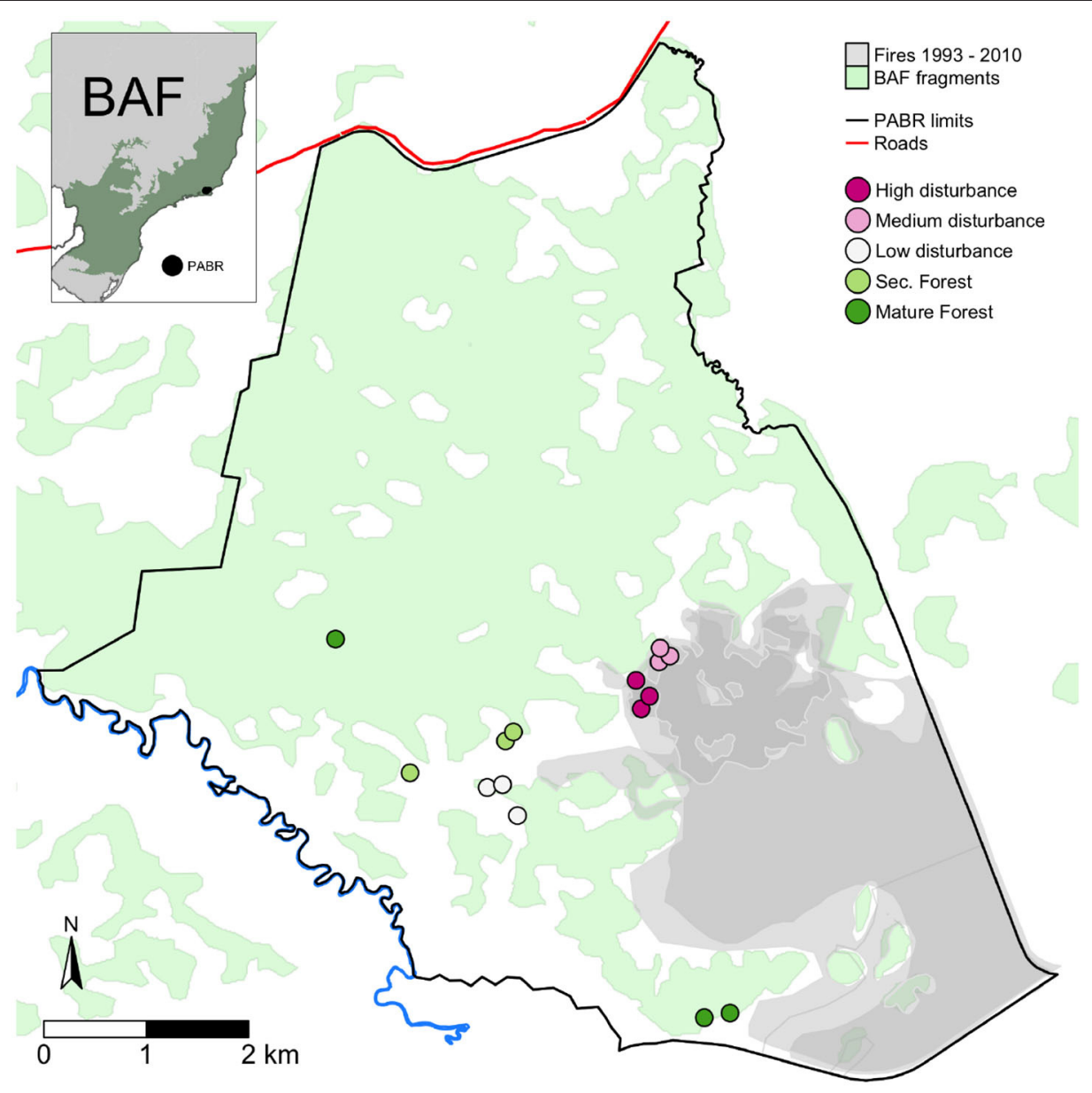

FIGURE 1 | The study area at the Poço das Antas Biological Reserve (PABR, black line), a Biological Reserve located in the eastern portion of the Brazilian Atlantic Forest (BAF). The green area in the inset map corresponds to the official limits of the BAF (IBGE, 2019), and the remaining BAF forest fragments (SOS Mata Atlântica, 2010) are depicted in light green in the main map. We established the fire history since 1993-2010 (overlapping gray areas), from maps made by the PABR staff. An additional fire in 1990 has no official map but it affected the High, Medium, and Low disturbance areas (last burned in 1990). The burned areas are mostly abandoned pastures and peatlands, and we positioned our sampling plots along the pasture-to-forest transition, where vegetation is regenerating. Each point in the map corresponds to a $60 \times 30 \mathrm{~m}$ plot, subdivided in $10 \times 10 \mathrm{~m}$ subplots. The fire history is detailed in Table 1 .

calculated using Gap Light Analyzer Version 2.0 (Frazer et al., 2001). Percent grass cover was estimated visually in two $1 \times 2 \mathrm{~m}$ quadrats in each $10 \times 10 \mathrm{~m}$ subplot.

\subsection{Response Functional Traits}

To analyze the community response to the opposed effect of the fire regimes and secondary succession, we selected five functional response traits related to fire resistance and forest growth (Table 2).

- Specific leaf area (SLA, $\left.\mathrm{cm}^{2} / \mathrm{g}\right)$ is an indicator of the plant's light acquisition strategy (Weiher et al., 1999; Wright et al., 2004) and is expected to be higher in less disturbed areas (mature forests), for two reasons. On the one hand, it will contribute to maximizing light capture in low-light environments and therefore is expected to be higher in forests; on the other, thicker, heavier leaves with high longevity are expected in harsher environments (Díaz et al., 2016).
- Wood density relates inversely to relative growth rate, and lower values relate to fast growth and colonization ability in newly disturbed sites. In mature forests, wood density relates to plant longevity and long-term resistance to decay (Kraft et al., 2010; Larjavaara and Muller-Landau, 2010).

- Potential height is related to competitive capacity and light acquisition strategies, but also to plant longevity. We expected canopies to be taller in general in forest environments. We also expected a canopy stratification to appear with forest development, reflected in multimodal distributions or larger variances of this trait (Kunstler et al., 2016).

- Seed mass is related to the dispersal vs. survival tradeoff and dispersal syndromes (Westoby, 1998), and we expected it to be higher in forests due to the presence of plants with lower number of larger seeds, dispersed by animals, while the presence of smaller seeds-probably dispersed by wind is expected in open environments (Westoby, 1998). 
TABLE 1 | Environmental factors that compose the complex fire gradient.

\begin{tabular}{lcccc}
\hline Plot & Time post-fire & Fire events & Distance to the nearest propagule font $(\mathbf{m})$ & Longitude, Latitude \\
\hline 2010A & 0.5 & 4 & 130 & $-42.269,-22.557$ \\
2010B & 0.5 & 4 & 180 & $-42.268,-22.556$ \\
2010C & 0.5 & 4 & 65 & $-42.270,-22.555$ \\
2002A & 8 & 3 & 55 & $-42.267,-22.553$ \\
2002B & 8 & 3 & 50 & $-42.266,-22.553$ \\
2002C & 8 & 3 & 30 & $-42.267,-22.552$ \\
1990A & 20 & 1 & 75 & High \\
1990B & 20 & 1 & 30 & Medium \\
1990C & 20 & 1 & 30 & $-42.281,-22.567$ \\
SfA & $>36$ & 0 & 0 & $-42.284,-22.564$ \\
SsB & $>36$ & 0 & 0 & $-42.282,-22.564$ \\
SfC & $>36$ & 0 & 0 & $-42.282,-22.560$ \\
MfA & $>54$ & 0 & 0 & $-42.281,-22.560$ \\
MfB & $>54$ & 0 & 0 & $-42.291,-22.563$ \\
MfC & $>54$ & 0 & 0 & $-42.261,-22.584$ \\
\end{tabular}

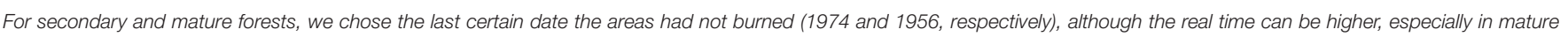
forest. Secondary forests were considered to be their own propagule source.

TABLE 2 | Functional response traits measured for this study, their units, and hypotheses related to fire resistance and forest growth.

\begin{tabular}{|c|c|c|c|}
\hline Trait & Unit & Hypothesis & References \\
\hline Specific Leaf Area (SLA) & & Higher in more shaded environment, lower in low-nutrient areas & $\begin{array}{l}\text { Poorter et al., 2009; Reich, } \\
2014\end{array}$ \\
\hline Plant height $(\mathrm{H})$ & $\mathrm{m}$ & Higher in forests, related to competitive ability, longevity, light acquisition & Westoby, 1998 \\
\hline Wood density (WD) & $\mathrm{g} / \mathrm{cm}^{3}$ & Higher in forests, related to longevity, slow growth & $\begin{array}{l}\text { Kraft et al., 2010; Larjavaara } \\
\text { and Muller-Landau, } 2010\end{array}$ \\
\hline Bark thickness (BT) & $\mathrm{mm}$ & Higher in areas with harsher fire regimes, related to fire survival, meristem protection & Pausas, 2014, 2017 \\
\hline Seed mass (SM) & g & Higher in forests, zoochory, coupled with lower seed number, higher investment per seed & Westoby, 1998 \\
\hline
\end{tabular}

- Bark thickness confers the ability to survive fire events (Hoffmann et al., 2009; Pausas, 2014) and was thus expected to be higher in areas more affected by the fire regime.

Leaf traits were collected from 1 to 8 individuals in the plots along the gradient. We found individuals for 121 of the 137 species present in the original species list, and followed Cornelissen et al. (2003) protocols. Twigs were collected and stored in the dark and refrigerated to avoid water loss. Individual leaves were cut in the laboratory underwater, to avoid cavitation, and their weight and area were measured. Bark thickness was measured from branch twigs (Paine et al., 2010), taking care of controlling for average diameter and position on the plant (i.e., not comparing twigs that were too thick with thinner twigs). We measured wood density from these twigs, by calculating the twig fresh volume following the volume replacement method and dividing it by its dry weight (Cornelissen et al., 2003). Potential height was assessed in the field, after calibration by two experienced persons and using marked leaf-cutter poles. Since most of the collected material was infertile, seed mass was measured from herbarium material. RB herbarium at the Rio de Janeiro Botanical Garden is the principal repository of botanical collections in Brazil, and the PABR has been thoroughly surveyed, therefore for all species it was possible to select botanical samples collected in the previous 10 years in the PABR or its close surroundings. This dataset was previously analyzed in Sansevero et al. (2020).

\subsection{Species Geographic Distribution}

Occurrence records for each species (see Supplementary Table 1) were downloaded from the Global Biodiversity Information Facility (GBIF) using rgbif package (Chamberlain et al., 2016) in the $\mathrm{R}$ statistical environment ( $\mathrm{R}$ Core Team, 2016). GBIF returns spatial coordinates of the species as recorded in botanical collections around the world. We removed geographic outliers and suspect coordinates (e.g., at the centroid of countries). We calculated the known area of distribution by rasterizing the occurrence points shapefile to a 2.5-min resolution WorldClim template, and counting the resulting pixels, thus calculating the Area of Occupancy (AOO; IUCN, 2001). Both the weighted and unweighted means of the distribution area (e.g., taking into account the dominance structure of communities or not) were calculated for each area along the gradient and used as a proxy to analyze the extent of the distribution area of the species composing the communities. 


\subsection{Generalization to Other Sites in the BAF}

We reviewed the Neotropical Tree Communities database (TreeCo) and the National Forest Inventory database (http://www.florestal.gov.br/inventario-florestal-nacional) to gather possible occurrences of the species in forest inventories in other regions of the BAF. Guided by these occurrence data, we visited and surveyed forest fragments larger than 0.5 ha, looking especially for the presence of $M$. polymorphum as a monodominant species (relative abundance above 60\%, Peh et al., 2011). At sites surveyed, monodominance was assessed visually, by taking into account the proportion of individuals from different species in relation to the total number of $M$. polymorphum individuals in the canopy. To obtain the stand size, we delimited manually the perimeter of each one using high-resolution satellite images (Google Earth) considering their color homogeneity, texture, and canopy pattern. We built a map of $M$. polymorphum monodominant sites in the visited areas in the BAF.

\subsection{Data Analysis}

To test the hypothesis that harsher fire regimes (e.g., more fire events and less recovery time) simplify forest structure and decrease their diversity, we compared the following variables along the fire gradient: (1) the relative dominance of $M$. polymorphum, (2) Simpson's diversity, (3) forest structure (mean tree height, tree density, mean tree ramification, total basal area, LAI), (4) percent grass cover.

To analyze functional trait composition and the Area of Occupancy (AOO) of each tree species present along the fire gradient, we calculated the community-weighted mean (CWM) of each studied functional response trait and of their AOO according to the following formula:

$$
C W M_{\text {trait }}=\sum_{n=1}^{S} p_{i j} * q_{i}
$$

where $p_{i}$ is the relative abundance of species $i$ in plot $j$ and $q_{i}$ is the mean trait value or the AOO of species $i$. We obtained thus a mean trait value per plot or subplot for each trait.

Comparisons of structural parameters and of functional response trait CWMs along the gradient were performed using a one-way permutation-based analysis of variance with posthoc pairwise tests as implemented by function aov . perm() in Basso et al. (2009), at the plot level (five areas, three plots per area).

A principal components analysis (PCA) was also performed on the vegetation structure data to understand the overall relationships between variables, at the subplot level $(n=90)$. To analyze taxonomic and functional turnover along the disturbance gradient, we calculated the Chord distance from the community matrix (121 species in the 90 subplots) and the Gower distance from the functional community-weighted mean trait matrix. We performed Principal Coordinates Analyses (PCoA) (Legendre and Gallagher, 2001) for both distance matrices. All analyses were performed in the R statistical environment, using the vegan community ecology package v.2.3-0 (Oksanen et al., 2016).

\section{RESULTS}

High disturbance areas were composed of mainly $M$. polymorphum individuals (Figure 2A), with a mean canopy height of $4.10 \mathrm{~m}$ (s.d. = 0.63), and multistemmed individuals. These areas had the lowest plant densities (Figure 2C) and LAI values (Figure 2D), and more than half of them had a continuous grass cover in the understory (Figure 2G). In consequence, Simpson's diversity was null in most plots (Figure 2B). High community-weighted mean (CWM) values for bark thickness and low CWM values for seed mass, wood density, and specific leaf area reflected the attributes of the dominant species.

Medium and Low disturbance areas, with more time since the last fire and less fire events, exhibited a recovery in structural parameters. Plant density (Figure 2C), canopy height (Figure 2D), basal area (Figure 2E), and LAI (Figure 2F) also increased at different rates along the fire gradient. However, secondary forests did not attain the canopy height or basal area of the old-growth reference forests. Dominance by $M$. polymorphum also decreased along the gradient, with less fire events and more time since the last fire. However, more than half of the plots in secondary forests still exhibited a relative density higher than 0.5 , and monodominance (r.d $>60 \%$ ) in almost $25 \%$ of them. The high dominance of the species along the gradient contrasts sharply with its complete absence from old-growth forests (Figure 2A).

Grass cover decreased sharply along the gradient (Figure 2G), from $100 \%$ cover in the High disturbance areas until the full exclusion of grasses in secondary forests. Reference oldgrowth forests had no grasses in their understory. Mean plant ramification decreased with milder fire regimes (Figure $\mathbf{2 H}$ ), not only due to the effect of species arrival since the individuals of $M$. polymorphum were also mostly multi-stemmed in more disturbed areas and mostly monopodial (i.e., having only one stem) in less disturbed areas. The PCA of the structural variables (Figure 3) reflected the structural recovery in terms of higher plant density, higher LAI, larger basal area and canopy height along the fire gradient, but differentiated the old-growth forests from the rest of the areas by having species with relatively small distribution areas and significantly higher basal areas and mean heights (Figure 3).

Likewise, mean community-weighted SLA, woody density, and seed mass increased, while bark thickness decreased along the gradient. In all cases, old-growth forests and secondary forests had significantly different values and larger ranges of CWM variation from High, Medium and Low disturbance areas (Figure 4). Values for wood density and seed mass were significantly higher and more variable in mature reference forests than in the rest of the gradient.

Structural changes were accompanied by an increase in Simpson's diversity (Figure 2B), but regeneration processes along the gradient included few species present in any of the reference old-growth forests. In fact, reference old-growth areas shared only 11 of the 96 species with any of the other areas (Supplementary Table 1). The taxonomic composition was strikingly different between old-growth forests and the rest of the 

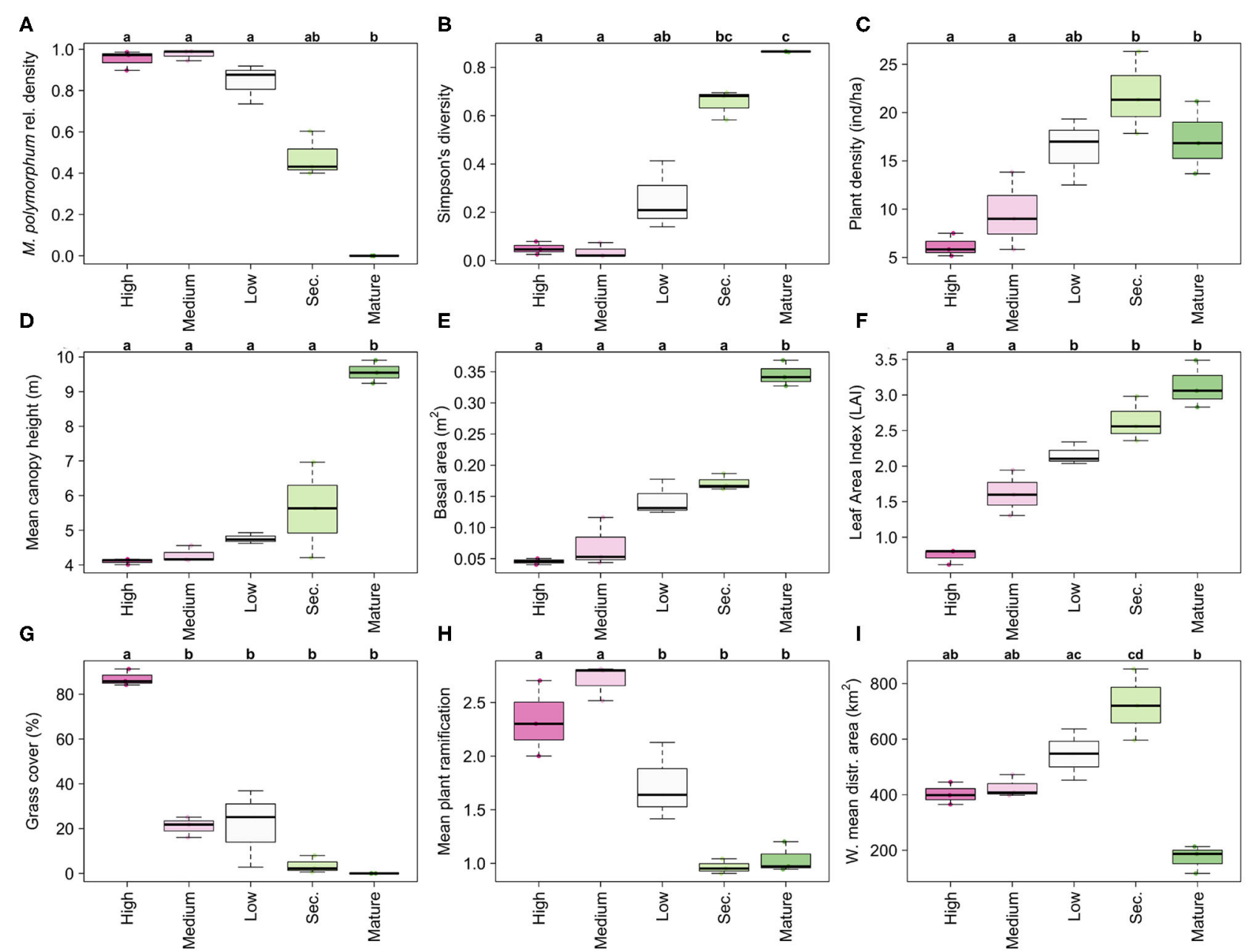

FIGURE 2 | Diversity and structure of secondary vegetation along a fire gradient that combines an increasing number of fire events and less time for recovery. High disturbance: four fire events and 0.5 years post-fire. Medium disturbance: three fire events and 8 years post-fire. Low disturbance: one fire event and 20 years post-fire. Secondary forests: no fire events and at least 36 years of regeneration. Old-growth forests, no fire events and they were confirmed forests since 1956 (at least 54 years of regeneration but possibly more). (A) Relative dominance of Moquiniastrum polymorphum, (B) Simpson's diversity, (C) plant density, (D) mean canopy height, (E) total basal area, (F) Leaf Area Index (LAl), (G) percent grass cover and (H) mean plant ramification increased with lower disturbance intensity, indicating the structural recovery of secondary vegetation. (I) The mean area of distribution of the species increased from harsher to milder fire regimes and peaked in secondary forests, but the reference mature forests had the lowest values. Letters indicate significance groups $(\alpha=0.05)$ following a permutation-based ANOVA with a post-hoc pairwise comparison (Basso et al., 2009). The statistics for these comparisons are in Supplementary Material.

fire gradient, regardless of their fire regime (Figure 5A, 48.52\% of the explained variation along the first axis). Species turnover between high, medium, and low disturbance areas followed a linear trajectory that converged toward the composition of secondary forests, but diverged from the composition of mature forests, as shown by the second PCoA axis (10.37\% Figure 5A). Most of the high and medium disturbance areas had almost the same composition, and variation along this axis came mainly from turnover between low disturbance areas and secondary forest areas.

In addition to the divergence in composition, species recruited in burned and secondary forests had significantly larger geographic distribution than species present in mature forests. The mean distribution area of species in high and medium disturbance areas (weighted or not by community abundance vectors) reflected mostly the geographic distribution of the monodominant $M$. polymorphum (Figure 2I). The mean geographic area was the main factor that differentiated the secondary forest structure from the rest of the gradient (Figure 3). In contrast to this tendency to recruit widelydistributed species, the species present in old-growth forest areas had consistently lower mean distribution areas than the rest of the species in the area.

Regarding the distribution of $M$. polymorphum in other abandoned pastures in the BAF, we recorded 74 areas of abandoned pastures that exhibited a monodominance of $M$. polymorphum in the visited sites (Figure 6).

The functional composition along the fire gradient converged toward the functional composition of some of the mature forests (Figure 5B, contrasting with the divergence in taxonomic 


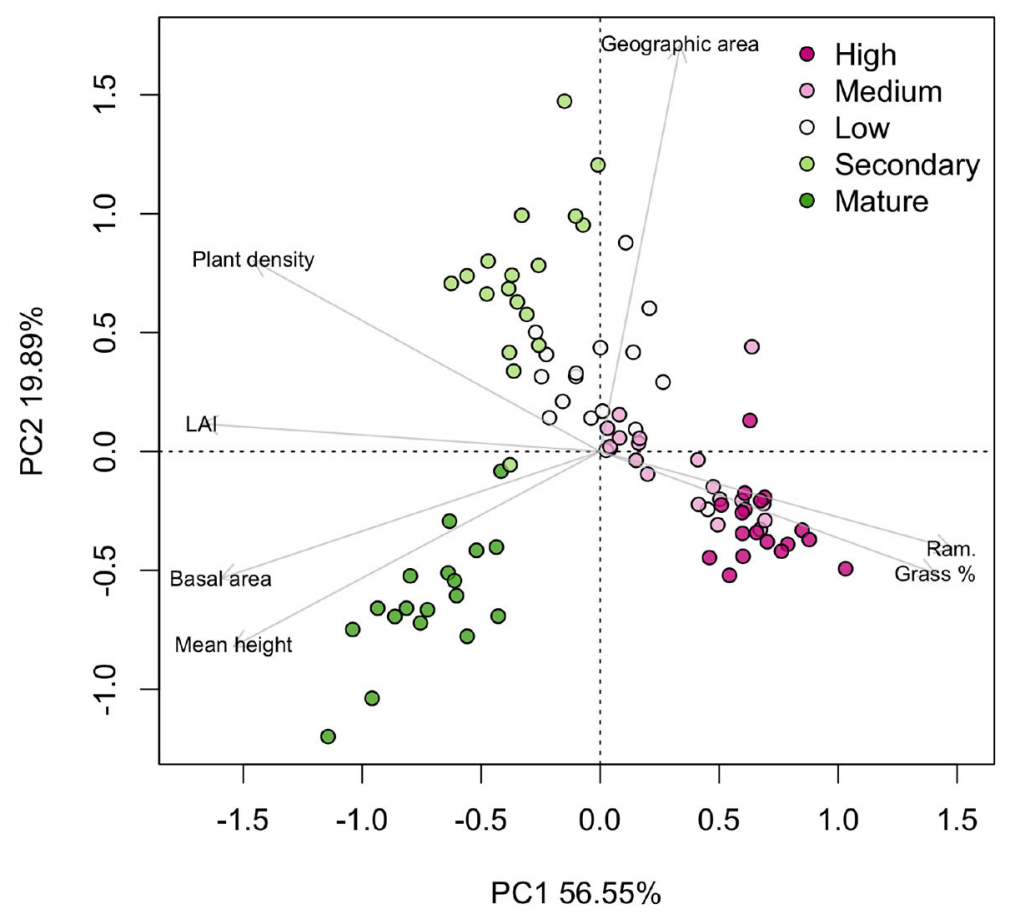

FIGURE 3 | PCA of the structural parameters along a fire gradient that combines an increasing number of fire events and less time for recovery. High disturbance: four fire events and 0.5 years post-fire. Medium disturbance: three fire events and 8 years post-fire. Low disturbance: one fire event and 20 years post-fire. Secondary forests: no fire events and at least 36 years of regeneration. Old-growth forests, no fire events and they were confirmed forests since 1956 (at least 54 years of regeneration but possibly more). Each point represents a $10 \times 10 \mathrm{~m}$ subplot in three plots per area $(n=90)$. High percent grass cover and plant ramification characterized the areas with harsher fire regimes. Plant density, LAl, basal area, and mean canopy height increased with milder fire regimes. Mature reference forest had the highest basal area and mean canopy height. Large species geographic distribution areas separated the secondary forests from the rest of the gradient.

composition. The functional turnover along the gradient was extremely high, with the first PCoA axis accounting for $83 \%$ of the variation in functional composition and corresponding to the differences between all the burned sites and the mature forests. Old-growth functional turnover appears along the second PCoA axis ( $12.7 \%$ of variation).

\section{DISCUSSION}

Our results show how the establishment of a fire-resistant species helps the system break the fire-grass cycles that dominate the area. Some of the characteristics of the subsequent regeneration point to recovery with milder fire regimes (i.e., longer postfire time and lower fire frequency), which confirms our initial hypotheses about the effect of less fire events and more time leading to recovery in forest structure and diversity. On the other hand, the presence of $M$. polymorphum generates a divergent pathway toward novel, impoverished forests composed of widelydistributed, generalist species. In the following sections, we analyze this duality in terms of a glass-half-full or glass-halfempty dilemma because success in passive and active restoration activities (i.e., the "desirability" of the outcomes) depends on the specific context in which restoration takes place, especially in human-modified landscapes. If the desired outcome is tree cover or carbon sequestration, some secondary forests may be providing already the sufficient ecosystem services to attain such goals, and no active restoration would be needed. It the outcomes are aiming to the recovery of biodiversity, cultural ecosystem services, or food provision, for instance, the outcome of natural regeneration may be insufficient (Lamb et al., 2005).

The studied areas occur in the transition from abandoned pastures trapped in the fire-grass cycle (sensu D'Antonio and Vitousek, 1992) to old-growth forests (Figure 1). These areas were pastures in 1956 and their current vegetation corresponds to the outcome of natural regeneration in the presence of different fire regimes. We thus cannot say that either "retrogressive succession" (Tabarelli et al., 2008) or "secondarization" (Barlow and Peres, 2008) happened in this system, since the studied fire gradient does not represent the erosion of standing forest fragments because of fire, as observed for some forests in the Amazon, where selective logging and surrounding fires interact to tip the forests to fire-prone states (Nepstad et al., 1999). Disentangling the specific effects of fire frequency and post-fire recovery time goes beyond the scope of this study and may prove impossible without experimental manipulation. However, the effects of both factors are directly related, so this does not impede the analysis of the regeneration taking place along the fire disturbance intensity gradient.

M. polymorphum is the main species from the regional species pool able to establish and persist in the abandoned 

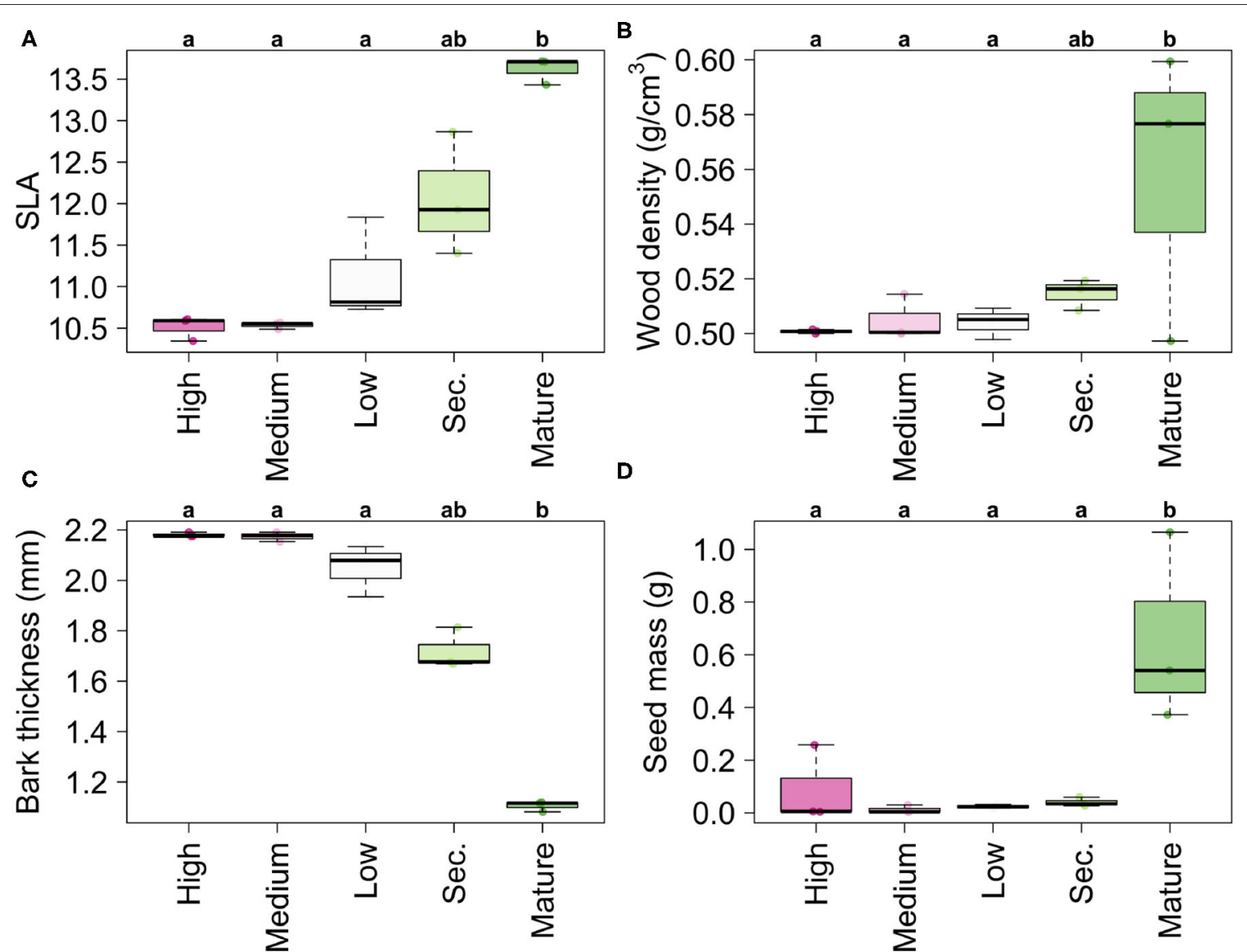

FIGURE 4 | Community-weighted values for the following functional traits: (A) Specific Leaf Area, (B) Wood density, (C) Bark thickness, (D) Seed mass along the disturbance gradient, from areas with high disturbance frequency to Mature Forests. Letters indicate significance groups $(\alpha=0.05)$ following a permutation-based pairwise comparison. The statistics for these comparisons are in Supplementary Material (Basso et al., 2009).

pastures. The mechanism by which it establishes deserves further study, since we sampled individuals with $\mathrm{dbh} \geq 5 \mathrm{~cm}$ and very few juvenile individuals are present among the grasses in the understory. Previous studies have shown that the species can flower and disperse its small, wind-dispersed seeds continuously, even shortly after fire events (Kolb, 1993). Due to the continuous propagule pressure, the species may find opportunities for colonization when grasses are suppressed by fire. Fire-free intervals allow individuals of the species to attain fire-resistance thanks to functional response traits like bark thickness (Pausas, 2014, 2017). This has been observed in tropical savannas, where the first key threshold for savanna-to-forest transitions is that established individuals survive fires and impede further fires to reset the community entirely (Hoffmann et al., 2012).

The vegetation structure in High disturbance areas, burned only 6 months before our measurements, confirms previous observations that the individuals of the species survive fire as reproductive adults (Prieto et al., 2017; Sansevero et al., 2017; Brandes et al., 2019). M. polymorphum individuals that attain fire resistance and survive fire events act as a template for regeneration. In the PABR, another species that can establish in the repeatedly burned pastures is the palm Attalea humilis Mart. ex. Spreng., but the species is not resistant to fire but resprouts after fire events (it occupies the "persistence niche" sensu Bond and Midgley, 2001). Therefore, it does not confer structure to the vegetation or facilitates the establishment of other species, as a remnant tree would do. Remnant trees play a key role in triggering regeneration following disturbance in some tropical forests (Holl et al., 2000; Hooper et al., 2005), but in the case of repeatedly burned pastures, species without fireresistance traits are unable to survive (Bond and Midgley, 2001; Hoffmann et al., 2003), which forces a shift in composition after the fire. This would explain the absence of fire-sensitive pioneer species that are common in other regions of the BAF, such as Trema micrantha (L.) Blume and Cecropia spp. (Silva-Matos et al., 2005). In the Cerrado (Brazilian savanna), where fire is an endogenous disturbance, the transition from burned grassland to fire-resistant forests also depends on the establishment of fire-resistant species (Hoffmann et al., 2012). In highlymodified landscapes, pioneer, widely-distributed species and even allochthonous species can be favored for having functional response traits that are key for survival under the modified 

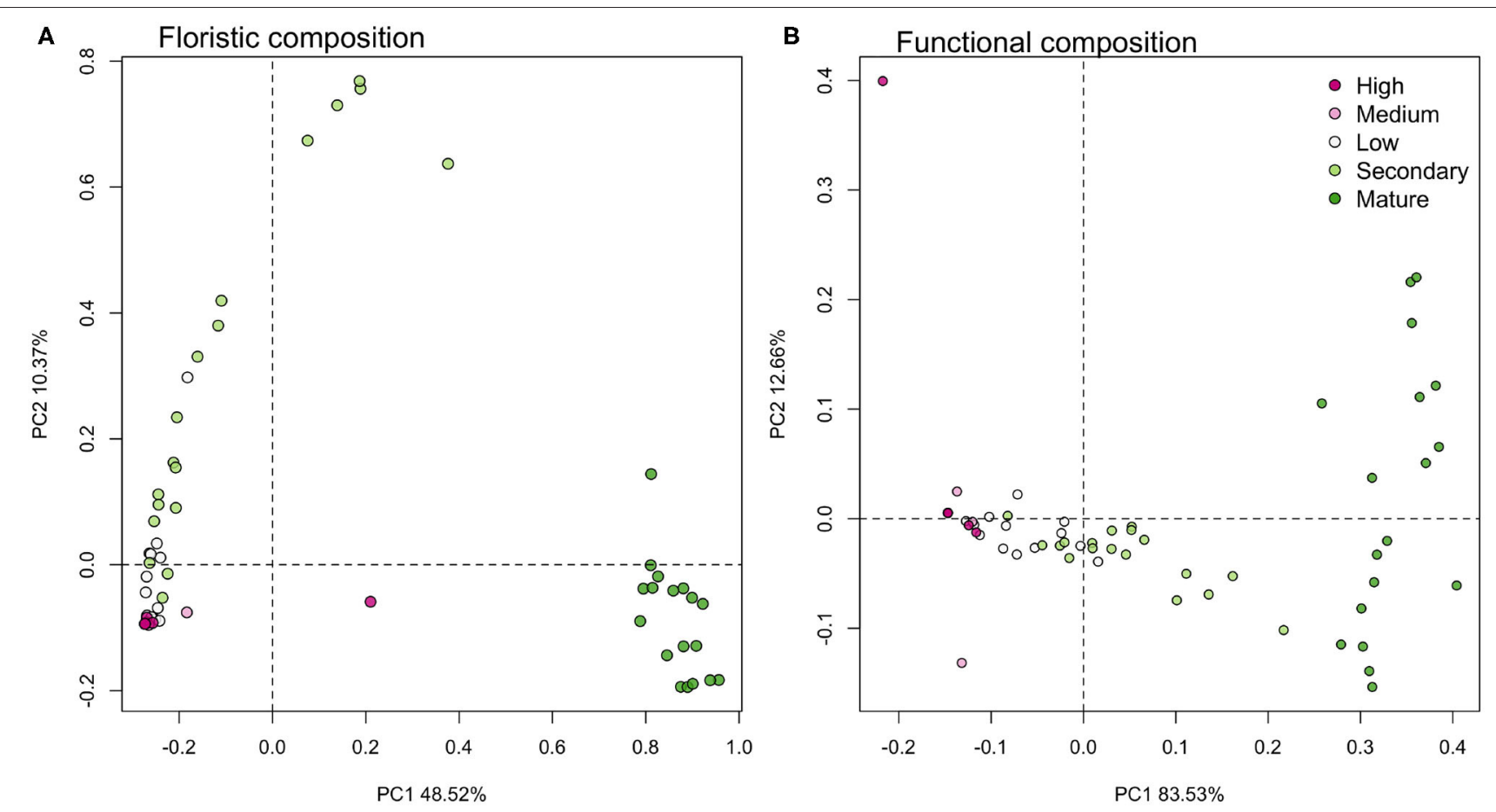

FIGURE 5 | (A) Taxonomic turnover along the fire gradient showed divergent floristic compositions between recovering burned areas and old-growth areas. Along the gradient, burned areas remained strinkingly different from reference old-growth areas (PC1), and their floristic composition diverged orthogonally, along the PC2. (B) Functional composition reflected the structural recovery of the vegetation along the gradient, in spite of the lack of floristic affinity, from High disturbance areas to Secondary Forests along PC1 and toward the functional composition of reference old-growth forests. Variation in the functional composition among mature forests is independent from this recovery and can be seen along PC2 axis. Each point represents a $10 \times 10 \mathrm{~m}$ subplot in three plots per area ( $n=90$ ).

disturbance regime (Carpenter et al., 2004). Similar shifts in dominance have been discussed previously on several occasions, for example by Uhl et al. (1988) and Mesquita et al. (2001) for post-fire Vismia dominance in Amazonian forest and Santana et al. (2010) for Rosmarinus officinalis in temperate forests.

High disturbance areas have the lowest LAI values, that fail to exclude grasses in the understory and suppress fires. In addition to mortality due to fires, other species arriving in the areas are subjected to increasing competition with grasses during fire-free intervals and an excess light environment unsuitable for shadedependent species. This hinders the early establishment of other species in these pastures, and perpetuates the monodominant state for a long time, as seen in the lack of significant differences between high and medium disturbance areas and the high dominance of the species even in the low disturbance areas. Studies on tropical forest succession have demonstrated that the first decades of succession can indeed be very slow (Uhl et al., 1988; Finegan, 1996), and the presence of continuous fires may delay regeneration even more.

With a longer time without fire, sites dominated by M. polymorphum gradually turn into more benign environments for the establishment and survival of other species. LAI almost doubles, and grass cover falls from ca. $100 \%$ to ca. $4 \%$ along the gradient, which explains the lower fire frequency. The step where canopy closes, grasses are excluded, and fuel accumulation stops is the "fire suppression" threshold described in pasture-to-forest transitions in the Cerrado and leads the herbaceous state toward a forested one, mostly uninfluenced by fire (Hoffmann et al., 2012). An increase in Simpson's diversity and basal area was observed between low disturbance sites and secondary forests, marking the stage at which most of the recruitment happens. Despite the milder environmental conditions, few species present in mature forests establish in these areas, and most of the species that enter the communities have significantly larger distribution areas than species present in old-growth areas. This floristic impoverishment reveals that fire has long-term effects, modifying the community assembly processes in pastures and diverting successional trajectories.

The appearance of $M$. polymorphum-dominated communities in the repeatedly burned pastures poses a glass-half-full/glasshalf-empty situation, in which the outcomes are perceived as positive or negative depending on the observer's perspective and aims (Arroyo-Rodríguez et al., 2017). On the one hand, pastures caught in the fire-grass feedback represent an undesired state for biodiversity conservation, carbon emissions, and soil integrity, among others (D'Antonio and Vitousek, 1992; Veldman and Putz, 2011). Any natural process that breaks this feedback is significant, and in this sense $M$. polymorphum-dominated stands constitute more desirable states than abandoned pastures. Monodominated stands of the species can act as shelter and 


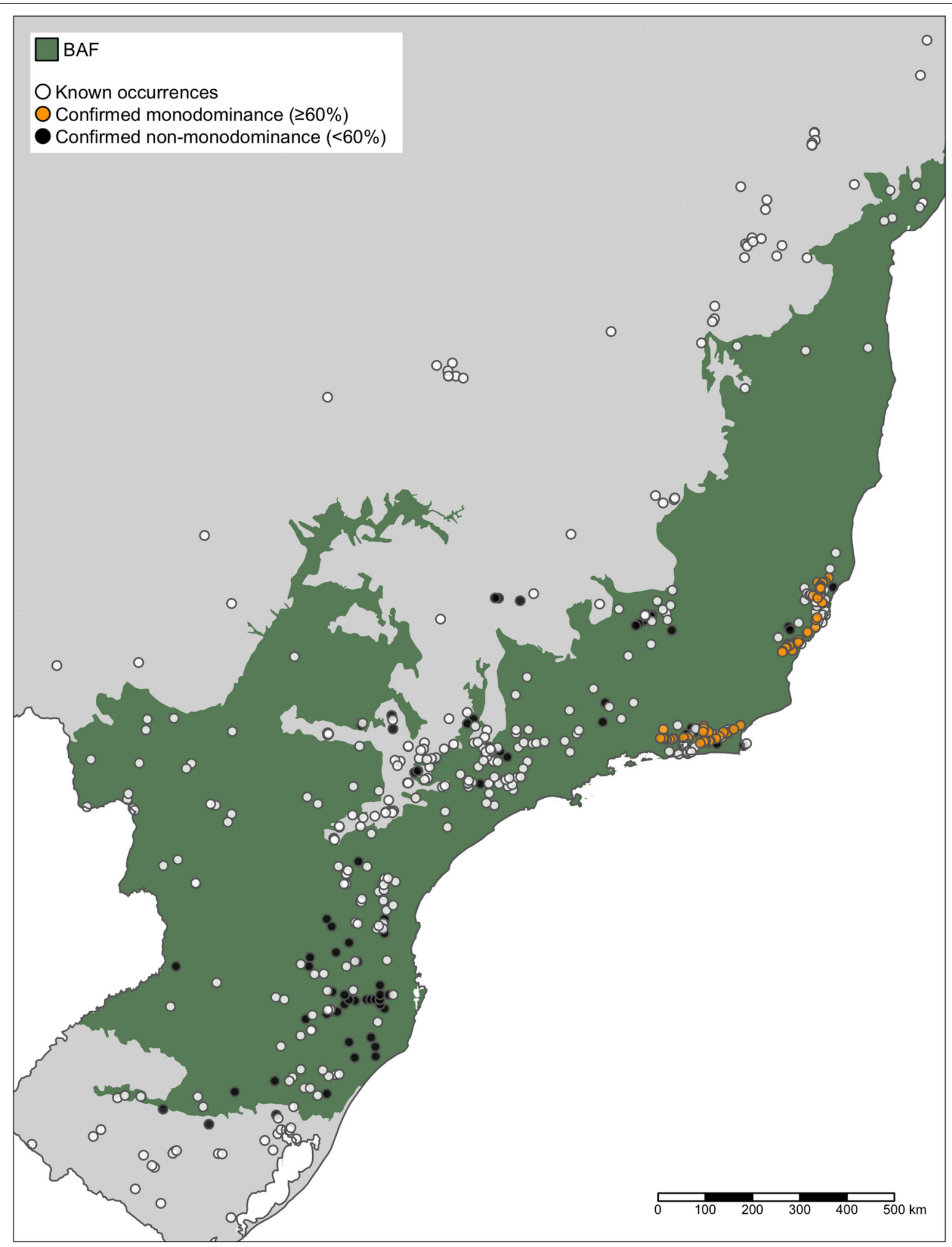

FIGURE 6 | Occurrence records for Moquiniastrum polymorphum along its whole area of distribution. We visited the areas with symbols in black and orange. Orange symbols indicate sites where the species was present as a monodominant (more than $60 \%$ relative abundance) and black symbols indicate sites where the species was present but not monodominant. The shaded green area corresponds to the official limits of the Brazilian Atlantic Forest (BAF; IBGE, 2019). 
perches for fauna, promoting the dispersal of other plant species, and they can provide resources for pollinators. On the other hand, succession in these areas is very slow, monodominated stages persist for a long time, and the secondary forests are composed mainly of widely-distributed species, with a few forest and fire-adapted elements. A previous study carried out in low and medium disturbance sites showed low biomass and species richness resilience compared to other Neotropical secondary forests (Sansevero et al., 2017).

Many succession studies have concluded that floristic composition is one of the hardest parameters to recover and it should not be expected beforehand (Chazdon et al., 2007; Norden et al., 2015; Rozendaal et al., 2019). Choosing reference areas is also a key part of this comparison, since succession proceeds in idiosyncratic ways (Norden et al., 2015) and beta diversity is high in high-diversity regions, such as the BAF. Here, we have coupled comparisons regarding floristic composition with the size of the species' distribution area and the functional composition recovery, to avoid focusing in floristic composition as a target per se.

In the PABR, M. polymorphum is the only species in the regional species pool that can establish in repeatedly-burned areas, and it is totally absent from old-growth forests. The species is also widely distributed across the BAF (Figure 6) and the Brazilian Savanna (Cerrado). The BAF is heterogeneous and not covered fully by tropical rainforest, and the transition from Cerrado to BAF comprises semi-deciduous vegetation fragments that may act as corridors for Cerrado species, therefore the mere presence of M. polymorphum should not be taken as proof of modified fire regimes. However, the BAF has been severely degraded and the shifts from presence to monodominance were found in tropical rainforest portions, away from the ecotones from BA to Cerrado, which suggests that similar patterns of species assembly could be happening in these regions.

Our results highlight the need to assess regeneration processes at the local scale, in a qualitative way and not only in a quantitative way. Some studies have documented an increase in forest cover in the tropics (e.g., Aide et al. 2012 in Costa Rica and de Rezende et al., 2015; Rezende et al., 2018; dos Santos et al., 2019 , in the BAF) but the nature of the regeneration pathways is frequently ignored. Observing community composition directly and assessing both the functional composition and the provision of ecosystem services would also be helpful to understand if the observed secondary forest are recovering or stuck in lowfunctioning secondary forests.

Dominance-shifts and divergent successional trajectories, such as these may be occurring along the whole Atlantic Forest, given the long time degradation history of the biome (Dean, 1996; Joly et al., 2014), the increasing fire frequency (dos Santos et al., 2019; de Jesus et al., 2020), and the existence of many more areas dominated by $M$. polymorphum in several degraded areas in the biome (Figure 6). If no action is taken (i.e., if ecological restoration relies solely in natural regeneration in these areas), the system can swing between two stable states, depending on the fire regimes. Especially, further fires can reset the communities back to $M$. polymorphum monodominance. However, the resulting secondary forests may serve as templates for future forest recovery, especially for restoration by enrichment planting to increase species richness and to guide the natural regeneration toward a composition that aligns with biodiversity conservation (Jakovac et al., 2015). This would require (1) a better understanding and mapping of the fire regimes across the Biome, (2) actions to prevent further fires, (3) the control of grasses under the canopies to lower their flammability, and (4) the active restoration of these sites, as enrichment plantations, to help increase the LAI and guide the recovery of taxonomic composition. We make a call for forest restoration practitioners to go beyond the simplistic approach of deciding between passive or active restoration, and to combine available techniques when possible, to fulfill the large-scale targets for biodiversity conservation and ecological restoration in the biome.

\section{DATA AVAILABILITY STATEMENT}

The datasets presented in this study can be found in online repositories. The names of the repository/repositories and accession number(s) can be found below: https://github.com/ AndreaSanchezTapia/sanchez-tapia_ffgc_2020.

\section{AUTHOR CONTRIBUTIONS}

AS-T, JS, and FS conceived the research idea. AS-T and JS collected the data. AS-T performed the statistical analyses and wrote the manuscript, with contributions from JS, MG, and FS. JB made the taxonomical determination of all plant species in the area. PF made the field surveys and dominance calculations in other BAF sites. All authors discussed the results, commented, and approved the manuscript.

\section{FUNDING}

AS-T received a CNPq master's degree scholarship, a research scholarship by Projeto Nacional de Ações Público-Privadas para Biodiversidade - PROBIO II-PPBio and is currently a PNPD Post-doctoral Fellow at the Rio de Janeiro Botanical Garden (CAPES- Programa Nacional de Pós-Doutorado). MG and JS hold CNPq (Produtividade em Pesquisa) PQ2 grants. PF receives a Doctoral Student Scholarship from CAPES (Coordination for the Improvement of Higher Education Personnel).

\section{ACKNOWLEDGMENTS}

We thank Rafael Puglia and the rest of the ICMBio staff at the PABR for granting access to fire records and Adilson Martins Pintor, Antonio Tavares, and Juan Camilo Sánchez-Arcila for invaluable help in the field.

\section{SUPPLEMENTARY MATERIAL}

The Supplementary Material for this article can be found online at: https://www.frontiersin.org/articles/10.3389/ffgc.2020. 560912/full\#supplementary-material 


\section{REFERENCES}

Arroyo-Rodríguez, V., Melo, F. P. L., Martínez-Ramos, M., Bongers, F., Chazdon, R. L., Meave, J. A., et al. (2017). Multiple successional pathways in humanmodified tropical landscapes: new insights from forest succession, forest fragmentation and landscape ecology research. Biol. Rev. 92, 326-340. doi: 10.1111/brv.12231

Barlow, J., and Peres, C. A. (2008). Fire-mediated dieback and compositional cascade in an Amazonian forest. Philos. Trans. R. Soc. B Biol. Sci. 363, 1787-1794. doi: 10.1098/rstb.2007.0013

Basso, D., Pesarin, F., Salmaso, L., and Solari, A. (2009). Permutation Tests for Stochastic Ordering and ANOVA: Theory and Applications With R, Volume 194 of Lecture Notes in Statistics. London; New York, NY: Springer Verlag.

Bond, W. J., and Midgley, J. J. (2001). Ecology of sprouting in woody plants: the persistence niche. Trends Ecol. Evol. 16, 45-51. doi: 10.1016/S0169-5347(00)02033-4

Brandes, A. F. d. N., Sánchez-Tapia, A., Sansevero, J. B. B., Albuquerque, R. P., and Barros, C. F. (2019). Fire records in tree rings of Moquiniastrum polymorphum: potential for reconstructing fire history in the Brazilian Atlantic Forest. Acta Bot. Brasil. 33, 61-66. doi: 10.1590/0102-33062018abb0282

Brando, P. M., and Durigan, G. (2005). Changes in cerrado vegetation after disturbance by frost (São Paulo State, Brazil). Plant Ecol. 175, 205-215. doi: $10.1007 /$ s11258-005-0014-z

Brazilian Ministry of the Environment (2005). Plano de Manejo da Reserva Biológica de Poço das Antas. Technical report, Ministério de Meio Ambiente, Rio de Janeiro.

Carpenter, F. L., Doland Nichols, J., and Sandi, E. (2004). Early growth of native and exotic trees planted on degraded tropical pasture. For. Ecol. Manage. 196, 367-378. doi: 10.1016/j.foreco.2004.03.030

Cavelier, J., Aide, T., Santos, C., Eusse, A., and Dupuy, J. (1998). The savannization of moist forests in the Sierra Nevada de Santa Marta, Colombia. J. Biogeogr. 25, 901-912. doi: 10.1046/j.1365-2699.1998.00222.x

Chamberlain, S., Ram, K., Barve, V., and Mcglinn, D. (2016). Rgbif: Interface to the Global Biodiversity Information Facility API. R package version 0.9.4. Available online at: https://CRAN.R-project.org/package $=$ rgbif

Chazdon, R. L., Letcher, S. G., van Breugel, M., Martínez-Ramos, M., Bongers, F., and Finegan, B. (2007). Rates of change in tree communities of secondary neotropical forests following major disturbances. Philos. Trans. R. Soc. B Biol. Sci. 362, 273-289. doi: 10.1098/rstb.2006.1990

Cochrane, M. A. (2003). Fire science for rainforests. Nature 421, 913-919. doi: 10.1038/nature01437

Cornelissen, J. H. C., Lavorel, S., Garnier, E., Diaz, S., Buchmann, N., Gurvich, D. E., et al. (2003). A handbook of protocols for standardised and easy measurement of plant functional traits worldwide. Aust. J. Bot. 51, 335-380. doi: 10.1071/BT02124

Crouzeilles, R., Santiami, E., Rosa, M., Pugliese, L., Brancalion, P. H. S., Rodrigues, R. R., et al. (2019). There is hope for achieving ambitious Atlantic Forest restoration commitments. Perspect. Ecol. Conserv. 17, 80-83. doi: 10.1016/j.pecon.2019.04.003

D’Antonio, C. M., and Vitousek, P. M. (1992). Biological Invasions by exotic grasses, the grass/fire cycle, and global change. Annu. Rev. Ecol. Syst. 23, 63-87. doi: 10.1146/annurev.es.23.110192.000431

de Jesus, J. B., da Rosa, C. N., Barreto, Í. D. d. C., and Fernandes, M. M. (2020). Análise da incidência temporal, espacial e de tendência de fogo nos biomas e Unidades de Conservação do Brasil. Ciênc. Flores. 30, 176-191. doi: 10.5902/1980509837696

de Rezende, C. L., Uezu, A., Scarano, F. R., and Araujo, D. S. D. (2015). Atlantic Forest spontaneous regeneration at landscape scale. Biodiv. Conserv. 24, 2255-2272. doi: 10.1007/s10531-015-0980-y

Dean, W. (1996). A Ferro e Fogo. A História e a Devastaç̃ao Da Mata Atl`antica Brasileira. $S$ ao Paulo: Companhia das Letras.

Díaz, S., Kattge, J., Cornelissen, J. H. C., Wright, I. J., Lavorel, S., Dray, S., et al. (2016). The global spectrum of plant form and function. Nature 529, 167-171. doi: 10.1038/nature16489

dos Santos, J. F. C., Gleriani, J. M., Velloso, S. G. S., de Souza, G. S. A., do Amaral, C. H., Torres, F. T. P., et al. (2019). Wildfires as a major challenge for natural regeneration in Atlantic Forest. Sci. Total Environ. 650, 809-821. doi: $10.1016 /$ j.scitotenv.2018.09.016
Ewers, R. M., Andrade, A., Laurance, S. G., Camargo, J. L., Lovejoy, T. E., and Laurance, W. F. (2016). Predicted trajectories of tree community change in Amazonian rainforest fragments. Ecography 40, 26-35. doi: 10.1111/ecog.02585

Finegan, B. (1996). Pattern and process in neotropical secondary rain forests: the first 100 years of succession. Trends Ecol. Evol. 11, 119-124. doi: 10.1016/0169-5347(96)81090-1

Flores, B. M., Fagoaga, R., Nelson, B. W., and Holmgren, M. (2016). Repeated fires trap Amazonian blackwater floodplains in an open vegetation state. J. Appl. Ecol. 53, 1597-1603. doi: 10.1111/1365-2664.12687

Frazer, G. W., Fournier, R. A., Trofymow, J. A., and Hall, R. J. (2001). A comparison of digital and film fisheye photography for analysis of forest canopy structure and gap light transmission. Agric. Forest Meteorol. 109, 249-263. doi: 10.1016/S0168-1923(01)00274-X

Hirota, M., Holmgren, M., Van Nes, E. H., and Scheffer, M. (2011). Global resilience of tropical forest and Savanna to critical transitions. Science 334, 232-235. doi: 10.1126/science.1210657

Hoffmann, W. A., Adasme, R., Haridasan, M., T. de Carvalho, M., Geiger, E. L., Pereira, M. A., et al. (2009). Tree topkill, not mortality, governs the dynamics of savanna-forest boundaries under frequent fire in central Brazil. Ecology 90 , 1326-1337. doi: 10.1890/08-0741.1

Hoffmann, W. A., Geiger, E. L., Gotsch, S. G., Rossatto, D. R., Silva, L. C. R., Lau, O. L., et al. (2012). Ecological thresholds at the savanna-forest boundary: how plant traits, resources and fire govern the distribution of tropical biomes. Ecol. Lett. 15, 759-768. doi: 10.1111/j.1461-0248.2012.01789.x

Hoffmann, W. A., Orthen, B., and do Nascimento, P. K. V. (2003). Comparative fire ecology of tropical savanna and forest trees. Funct. Ecol. 17, 720-726. doi: $10.1111 / j .1365-2435.2003 .00796 . x$

Holl, K. D., Loik, M. E., Lin, E. H. V., and Samuels, I. A. (2000). Tropical Montane forest restoration in Costa Rica: overcoming barriers to dispersal and establishment. Restor. Ecol. 8, 339-349. doi: 10.1046/j.1526-100x.2000.80049.x

Hooper, E., Legendre, P., and Condit, R. (2005). Barriers to forest regeneration of deforested and abandoned land in Panama. J. Appl. Ecol. 42, 1165-1174. doi: 10.1111/j.1365-2664.2005.01106.x

IBGE (2019). Mapa de Biomas do Brasil. Rio de Janeiro, IBGE.

IUCN (2001). IUCN Red List Categories and Criteria. Gland: IUCN.

Jakovac, C. C., Pe na-Claros, M., Kuyper, T. W., and Bongers, F. (2015). Loss of secondary-forest resilience by land-use intensification in the Amazon. J. Ecol. 103, 67-77. doi: 10.1111/1365-2745.12298

Joly, C. A., Metzger, J. P., and Tabarelli, M. (2014). Experiences from the Brazilian Atlantic Forest: ecological findings and conservation initiatives. New Phytol. 204, 459-473. doi: 10.1111/nph.12989

Kolb, S. (1993). Islands of secondary vegetation in degraded pastures of Brazil: their role in reestablishing Atlantic coastal forest (Ph.D. dissertation), University of Georgia, Athens, GA, United States.

Köppen, W. (1936). "Das geographische System der Klimate," in Handbuch Der Klimatologie, Vol. 1, eds W. Köppen and R. Geiger (Berlin: Verlag von Gebrüder Borntraeger), 1-44.

Kraft, N. J. B., Metz, M. R., Condit, R. S., and Chave, J. (2010). The relationship between wood density and mortality in a global tropical forest data set. New Phytol. 188, 1124-1136. doi: 10.1111/j.1469-8137.2010.03444.x

Kunstler, G., Falster, D., Coomes, D. A., Hui, F., Kooyman, R. M., Laughlin, D. C., et al. (2016). Plant functional traits have globally consistent effects on competition. Nature 529, 204-207. doi: 10.1038/nature16476

Lamb, D., Erskine, P. D., and Parrotta, J. A. (2005). Restoration of degraded tropical forest landscapes. Science 310, 1628-1632. doi: 10.1126/science.1111773

Larjavaara, M., and Muller-Landau, H. C. (2010). Rethinking the value of high wood density. Funct. Ecol. 24, 701-705. doi: 10.1111/j.1365-2435.2010.01698.x

Legendre, P., and De Cáceres, M. (2013). Beta diversity as the variance of community data: dissimilarity coefficients and partitioning. Ecol. Lett. 16, 951-963. doi: 10.1111/ele.12141

Legendre, P., and Gallagher, E. D. (2001). Ecologically meaningful transformations for ordination of species data. Oecologia 129, 271-280. doi: $10.1007 /$ s004420100716

Lima, H., Pessoa, S., Guedes-Bruni, R., Moraes, L., Granzotto, S., Iwamoto, S., et al. (2006). Caracterização fisionômico-florística e mapeamento da vegetação da Reserva Biológica de Poço das Antas, Silva Jardim, Rio de Janeiro, Brasil. Rodriguésia 57, 369-389. doi: 10.1590/2175-78602006 57301 
Melo, F. P., Arroyo-Rodríguez, V., Fahrig, L., Martínez-Ramos, M., and Tabarelli, M. (2013). On the hope for biodiversity-friendly tropical landscapes. Trends Ecol. Evol. 28, 462-468. doi: 10.1016/j.tree.2013.01.001

Mesquita, R. C. G., Ickes, K., Ganade, G., and Williamson, G. B. (2001). Alternative successional pathways in the Amazon Basin. J. Ecol. 89, 528-537. doi: 10.1046/j.1365-2745.2001.00583.x

Nepstad, D. C., Verssimo, A., Alencar, A., Nobre, C., Lima, E., Lefebvre, P., et al. (1999). Large-scale impoverishment of Amazonian forests by logging and fire. Nature 398, 505-508. doi: 10.1038/19066

Norden, N., Angarita, H. A., Bongers, F., Martínez-Ramos, M., la Cerda, I. G., van Breugel, M., et al. (2015). Successional dynamics in Neotropical forests are as uncertain as they are predictable. Proc. Natl. Acad. Sci. U.S.A. 112, 8013-8018. doi: $10.1073 /$ pnas. 1500403112

Oksanen, J., Blanchet, F. G., Friendly, M., Kindt, R., Legendre, P., McGlinn, D., et al. (2016). Vegan: Community Ecology Package R Package Version 2.3-0. Available online at: https://CRAN.R-project.org/package=vegan

Paine, C. E. T., Stahl, C., Courtois, E. A., Pati no, S., Sarmiento, C., and Baraloto, C. (2010). Functional explanations for variation in bark thickness in tropical rain forest trees. Funct. Ecol. 24, 1202-1210. doi: 10.1111/j.1365-2435.2010.01736.x

Pausas, J. G. (2014). Bark thickness and fire regime. Funct. Ecol. 29, 315-327. doi: $10.1111 / 1365-2435.12372$

Pausas, J. G. (2015). Alternative fire-driven vegetation states. J. Veg. Sci. 26, 4-6. doi: $10.1111 /$ jvs.12237

Pausas, J. G. (2017). Bark thickness and fire regime: another twist. New Phytol. 213, 13-15. doi: 10.1111/nph.14277

Peh, K. S.-H., Lewis, S. L., and Lloyd, J. (2011). Mechanisms of monodominance in diverse tropical tree-dominated systems. J. Ecol. 99, 891-898. doi: $10.1111 / \mathrm{j} .1365-2745.2011 .01827 . \mathrm{x}$

Poorter, H., Niinemets, Ü., Poorter, L., Wright, I. J., and Villar, R. (2009). Causes and consequences of variation in leaf mass per area (LMA): a meta-analysis. New Phytol. 182, 565-588. doi: 10.1111/j.1469-8137.2009.02830.x

Prieto, P. V., Seger, G. D., Sánchez-Tapia, A., Sansevero, J. B., Braga, J. M., and Rodrigues, P. J. (2017). Secondary succession and fire disturbance promote dominance of a late-diverging tree lineage in a lowland neotropical forest. Plant Ecol. Divers. 10, 311-322. doi: 10.1080/17550874.2017.1379568

R Core Team (2016). R: A Language and Environment for Statistical Computing. Vienna: R Core Team.

Reich, P. B. (2014). The world-wide "fast-slow" plant economics spectrum: a traits manifesto. J. Ecol. 102, 275-301. doi: 10.1111/1365-2745.12211

Reyer, C. P. O., Brouwers, N., Rammig, A., Brook, B. W., Epila, J., Grant, R. F., et al. (2015). Forest resilience and tipping points at different spatio-temporal scales: approaches and challenges. J. Ecol. 103, 5-15. doi: 10.1111/1365-2745. 12337

Rezende, C. L., Scarano, F. R., Assad, E. D., Joly, C. A., Metzger, J. P., Strassburg, B. B. N., et al. (2018). From hotspot to hopespot: an opportunity for the Brazilian Atlantic Forest. Perspect. Ecol. Conserv. 16, 208-214. doi: 10.1016/j.pecon.2018.10.002

Rozendaal, D. M. A., Bongers, F., Aide, T. M., Alvarez-Dávila, E., Ascarrunz, N., Balvanera, P., et al. (2019). Biodiversity recovery of neotropical secondary forests. Sci. Adv. 5:eaau3114. doi: 10.1126/sciadv.aau3114

Sansevero, J. B. B., Garbin, M. L., Sánchez-Tapia, A., Valladares, F., and Scarano, F. R. (2020). Fire drives abandoned pastures to a savanna-like state in the Brazilian Atlantic Forest. Perspect. Ecol. Conserv. 18, 31-36. doi: 10.1016/j.pecon.2019.12.004

Sansevero, J. B. B., Prieto, P. V., Sánchez-Tapia, A., Braga, J. M. A., and Rodrigues, P. J. F. P. (2017). Past land-use and ecological resilience in a lowland Brazilian
Atlantic Forest: implications for passive restoration. New Forests 48, 573-586. doi: 10.1007/s11056-017-9586-4

Santana, V. M., Baeza, M. J., Marrs, R. H., and Vallejo, V. R. (2010). Old-field secondary succession in SE Spain: can fire divert it? Plant Ecol. 211, 337-349. doi: 10.1007/s11258-010-9793-y

Santos, B. A., Peres, C. A., Oliveira, M. A., Grillo, A., Alves-Costa, C. P., and Tabarelli, M. (2008). Drastic erosion in functional attributes of tree assemblages in Atlantic forest fragments of northeastern Brazil. Biol. Conserv. 141, 249-260. doi: 10.1016/j.biocon.2007.09.018

Silva-Matos, D. M., Fonseca, G. D. F. M., and Silva-Lima, L. (2005). Differences on post-fire regeneration of the pioneer trees Cecropia glazioui and Trema micrantha in a lowland Brazilian Atlantic Forest. Rev. Biol. Trop. 53, 1-4. doi: 10.15517/RBT.V53I1-2.14291

SOS Mata Atlântica (2010). Atlas da Mata Atlântica. São Paulo, SOS Mata Atlântica.

Suding, K. N., Gross, K. L., and Houseman, G. R. (2004). Alternative states and positive feedbacks in restoration ecology. Trends Ecol. Evol. 19, 46-53. doi: $10.1016 /$ j.tree.2003.10.005

Tabarelli, M., Aguiar, A. V., Ribeiro, M. C., Metzger, J. P., and Peres, C. A. (2010). Prospects for biodiversity conservation in the Atlantic Forest: lessons from aging human-modified landscapes. Biol. Conserv. 143, 2328-2340. doi: 10.1016/j.biocon.2010.02.005

Tabarelli, M., Lopes, A. V., and Peres, C. A. (2008). Edge-effects drive tropical forest fragments towards an early-successional system. Biotropica 40, 657-661. doi: 10.1111/j.1744-7429.2008.00454.x

Uhl, C., Buschbacher, R., and Serrao, E. A. S. (1988). Abandoned pastures in Eastern Amazonia. I. Patterns of plant succession. J. Ecol. 76:663. doi: $10.2307 / 2260566$

Veldman, J. W., and Putz, F. E. (2011). Grass-dominated vegetation, not species-diverse natural savanna, replaces degraded tropical forests on the southern edge of the Amazon basin. Biol. Conserv. 144, 1419-1429. doi: 10.1016/j.biocon.2011.01.011

Walker, L. R., Wardle, D. A., Bardgett, R. D., and Clarkson, B. D. (2010). The use of chronosequences in studies of ecological succession and soil development. J. Ecol. 98, 725-736. doi: 10.1111/j.1365-2745.2010.01664.x

Weiher, E., van der Werf, A., Thompson, K., Roderick, M., Garnier, E., and Eriksson, O. (1999). Challenging theophrastus: a common core list of plant traits for functional ecology. J. Veg. Sci. 10, 609-620. doi: 10.2307/ 3237076

Westoby, M. (1998). A leaf-height-seed (LHS) plant ecology strategy scheme. Plant Soil 199, 213-227. doi: 10.1023/A:1004327224729

Wright, I. J., Reich, P. B., Westoby, M., Ackerly, D. D., Baruch, Z., Bongers, F., et al. (2004). The worldwide leaf economics spectrum. Nature 428, 821-827. doi: $10.1038 /$ nature 02403

Conflict of Interest: The authors declare that the research was conducted in the absence of any commercial or financial relationships that could be construed as a potential conflict of interest.

Copyright (c) 2020 Sánchez-Tapia, Sansevero, Garbin, Braga, Figueiredo and Scarano. This is an open-access article distributed under the terms of the Creative Commons Attribution License (CC BY). The use, distribution or reproduction in other forums is permitted, provided the original author(s) and the copyright owner(s) are credited and that the original publication in this journal is cited, in accordance with accepted academic practice. No use, distribution or reproduction is permitted which does not comply with these terms. 